\title{
Linguagem, Cognição e Educação Infantil: Contribuições da Psicologia Cognitiva e das Neurociências
}

\author{
Renan de Almeida Sargiani' ${ }^{1}$; https://orcid.org/0000-0002-6520-6515 \\ Maria Regina Maluf'; https://orcid.org/0000-0001-9132-5502
}

\begin{abstract}
Resumo
Profissionais de Educação Infantil frequentemente recomendam que educadores adotem práticas que favoreçam o desenvolvimento da linguagem oral nos currículos, mas o mesmo não ocorre com a linguagem escrita, que embora também esteja presente no cotidiano das crianças, é majoritariamente assunto posposto e controverso. Essas posições frequentemente ignoram pesquisas recentes da Psicologia Cognitiva e das Neurociências que se dedicam ao estudo das relações entre o desenvolvimento cognitivo e da linguagem. Trata-se de estudos que trazem novas explicações e abrem perspectivas para a prevenção de dificuldades e a preparação da alfabetização. Neste artigo teórico são discutidas algumas dessas contribuições voltadas para o entendimento dos processos cognitivos e mecanismos cerebrais presentes na aprendizagem da leitura e da escrita em sistemas alfabéticos, como é o caso do português brasileiro.
\end{abstract}

Palavras-chave: Alfabetização; Educação Infantil; Psicologia Cognitiva.

\section{Language, Cognition and Early Childhood Education: Contributions of Cognitive Psychology and Neuroscience}

\begin{abstract}
The Early Childhood professionals often recommend that educators adopt practices that favor the development of oral language in curricula, but the same does not occur with written language, which although it is also present in children's daily lives, is mostly a postponed and controversial subject. These positions often ignore recent research from Cognitive Psychology and Neuroscience that is devoted to the study of the relationships between cognitive and language development. These are studies that bring new explanations and open perspectives for the prevention of difficulties and the preparation of literacy. This theoretical article discusses some of these contributions aimed at understanding the cognitive processes and brain mechanisms present in the learning of reading and writing in alphabetical systems, as is the case of Brazilian Portuguese.
\end{abstract}

Keywords: Literacy; Early Childhood Education; Cognitive Psychology.

\section{Lenguaje, Cognición y Educación infantil: Contribuciones de la Psicología}

\section{Cognitiva y de las Neurociencias}

\section{Resumen}

Profesionales de Educación Infantil frecuentemente recomiendan que educadores adopten prácticas que favorezcan el desarrollo del lenguaje oral en los currículos, sin embargo, igual no ocurre con el lenguaje escrita, aunque también estén presente en el cotidiano de los niños, es mayoritariamente tema pospuesto y polémico. Esas posiciones frecuentemente ignoran investigaciones recientes de la Psicología Cognitiva y de las Neurociencias que se dedican al estudio de las relaciones entre el desarrollo cognitivo y del lenguaje. Se trata de estudios que traen nuevas explicaciones y abren perspectivas a la prevención de dificultades y la preparación de la alfabetización. En este artículo teórico se discute algunas de esas contribuciones volcadas al entendimiento de los procesos cognitivos y mecanismos cerebrales presentes en el aprendizaje de la lectura y de la escritura en sistemas alfabéticos, como es el caso del portugués brasileño.

Palabras clave: Alfabetización; Educación Infantil; Psicología Cognitiva.

1 Pontifícia Universidade Católica de São Paulo - São Paulo - SP - Brasil; sargiani@gmail.com; marmaluf@gmail.com 


\section{Introdução}

O desenvolvimento cognitivo está associado ao desenvolvimento linguístico. Quanto melhor for o desenvolvimento da linguagem das crianças, mais hábeis elas serão em comunicar seus pensamentos, sentimentos, ideias, intenções e também compreender os mesmos processos nos outros (Zauche, Thul, Mahoney, \& Stapel-Wax, 2016). Não por acaso, educadores e pesquisadores recomendam que os currículos de Educação Infantil estimulem e promovam o desenvolvimento da linguagem oral na pré-escola. Entretanto, o mesmo não ocorre com a linguagem escrita, que embora também esteja presente no cotidiano das crianças e contribua para o desenvolvimento cognitivo, é majoritariamente assunto posposto e controverso para muitos profissionais de Educação Infantil (Arce \& Martins, 2007).

Neste artigo, realizamos uma revisão de literatura com o objetivo de contribuir para a reflexão sobre as práticas de ensino relacionadas à linguagem oral e escrita na Educação Infantil, propiciando uma base referencial para que psicólogos educacionais, psicólogos escolares, psicopedagogos, professores e educadores possam se beneficiar do conhecimento mais atual sobre o desenvolvimento infantil e aprendizagem da linguagem escrita e apoiar sua atuação em evidências cientificas recentes.

\section{Práticas de linguagem oral e escrita na Educação Infantil}

Ao ingressar nas escolas de Educação Infantil (pré-escolas) aos 4 ou 5 anos, as crianças já possuem muitas diferenças nos conhecimentos e habilidades que serão necessários para as aprendizagens ulteriores no Ensino Fundamental. Essas diferenças são de origens diversas, podendo ser de origem genética sim, mas, sobretudo, são de origem cultural e socioeconômica (Burger, 2010; Stein \& cols., 2013)

Crianças de famílias em condições de vulnerabilidade social encontram-se em situações desprivilegiadas por uma série de fatores, como a falta de acesso a condições básicas de higiene, segurança e alimentação, mas também pela dificuldade de acesso aos bens culturais que incluem, por exemplo, a experiência com livros e revistas (Tunmer, 2013; Tunmer, Chapman, \& Prochnow, 2006). Além disso, as crianças em condições de vulnerabilidade social frequentemente apresentam defasagem em seu desenvolvimento linguístico, ex., reduzida amplitude do vocabulário oral, que se não for superada na Educação Infantil dificultará o seu processo de escolarização (Kuhl, 2011; Maluf, 2015; Zauche \& cols., 2016).

O desenvolvimento do vocabulário durante os anos pré-escolares é muito importante, pois está relacionado com a posterior aquisição das habilidades de leitura e escrita e com o sucesso escolar em geral. As diferenças individuais no desenvolvimento do vocabulário são influenciadas pelas experiências ambientais, por exemplo, pelo número de interações verbais entre pais e filhos. Crianças de famílias de baixo nível socioeconômico ouvem em média metade das palavras (616 palavras por hora) que crianças filhas de trabalhadores de nível médio (1251 palavras por hora) e menos de um terço da quantidade de palavras que crianças filhas de profissionais liberais com formação superior (2153 palavras por hora) (Hart \& Risley, 1995). Como consequência disso, por volta dos três anos de idade, as crianças de famílias de alta renda são expostas a 30 milhões de palavras a mais do que as crianças de famílias de baixa renda, o que influenciará na sua amplitude de vocabulário oral, no processo de escolarização dessas crianças e em sua vida de modo geral (Hart \& Risley, 2003).

Durante os seis primeiros anos de vida, as crianças aprendem muitas habilidades linguísticas e cognitivas importantes que são os pilares necessários para o sucesso escolar. É nesse período que a arquitetura cerebral se forma a partir da interação dos genes das crianças com as experiências, relacionamentos e o ambiente em que vivem. A complexidade dos estímulos linguísticos que as crianças recebem é um fator significativo no desenvolvimento de áreas do cérebro relacionadas à linguagem (Kuhl, 2011) Muitos estudos mostram que as diferenças individuais das crianças na Educação Infantil podem persistir e se intensificar nos anos posteriores de escolarização,limitando ou ampliando o sucesso na aprendizagem escolar (Burger, 2010; Zauche \& cols., 2016).

As crianças pequenas que demonstram proficiência em linguagem oral e habilidades iniciais do processamento da linguagem escrita, na Educação Infantil, têm melhores desempenhos na aprendizagem da leitura consistentemente ao longo dos três primeiros anos do Ensino Fundamental (Scarborough, 2001). As desvantagens existentes no período da Educação Infantil perduram no processo de escolarização e têm vários efeitos em diferentes áreas ao longo da vida; mas bons programas de Educação Infantil podem contribuir para a superação dessas desvantagens, também com efeitos duradouros (Burger, 2010).

Ao proporcionar experiências sociais e cognitivas de qualidade, os programas de educação pré-escolar podem fomentar o desenvolvimento das crianças e complementar as experiências recebidas em casa com a família (Stein \& cols., 2013; Zauche \& cols., 2016). Assim, garantir que as crianças recebam ensino de qualidade na Educação Infantil e adquiram os precursores das habilidades de leitura e escrita nesta fase deve ser encarado como um direito das crianças, bem como um meio de beneficiar todo o seu processo de escolarização ulterior e, portanto, um dever das creches, escolas, pais, professores e governos.

No Brasil, as práticas de Educação Infantil têm historicamente evoluído a partir de um modelo assistencialista, de apenas fornecer cuidados básicos como a higiene, segurança e alimentação, pouco fundamentado em métodos sistemáticos de ensino que preparem para a escolarização posterior (Arce \& Martins, 2007; Silva \& Hai, 2013). Embora se possa constatar que houve uma evolução nas últimas décadas, alguns especialistas brasileiros e estrangeiros ainda 
afirmam que a Educação Infantil deve limitar-se a ser um espaço para brincar e vivenciar situações as quais as crianças não poderão experimentar nas escolas posteriormente (Abramowicz, Levcovitz, \& Rodrigues, 2009). Contudo, outros argumentam que ela é um espaço crucial para preparar as crianças para os anos vindouros e que isso pode ser feito com a utilização de métodos lúdicos (Arce \& Martins, 2007; Silva \& Hai, 2013).

Adota-se aqui a ideia de que a Educação Infantil deve sim garantir que as crianças adquiram habilidades básicas que facilitem seu percurso no Ensino Fundamental, de modo que a ruptura entre esses dois níveis de ensino seja minimizada e a adaptação ao ensino sistemático seja facilitada, o que pode ser feito sem nenhum prejuízo das atividades lúdicas. Promover o desenvolvimento de habilidades essenciais para a escolarização na Educação Infantil não é excluir os direitos das crianças de brincar e vivenciar a sua infância. Na verdade é o oposto, é garantir-lhes o direito do acesso igualitário a condições básicas de interagir e entender informações que estão ao seu redor (como a leitura e a escrita), promover sua autonomia, garantir que tenham mais tempo para lidar com suas possíveis dificuldades e desenvolver suas potencialidades, vivenciando plenamente a sua infância, bem como minimizar os efeitos das lacunas existentes devido a diferenças individuais, culturais e socioeconômicas e diminuir a ruptura abrupta entre o modelo de Educação Infantil e o modelo adotado nas escolas de Ensino Fundamental.

As atividades desenvolvidas na Educação Infantil podem ser ao mesmo tempo lúdicas e instrutivas, garantindo o desenvolvimento de habilidades necessárias para os anos seguintes de escolarização, sem privar as crianças de outras vivências e aprendizagens comuns à Educação Infantil. Nesse sentido, considera-se que a decisão sobre as melhores estratégias de ensino e os conteúdos a serem ensinados deve ser fundamentada em pesquisas científicas que permitam balizar o que será feito a partir de evidências e não de opiniões, crenças e ideologias. Deve-se também considerar que a ciência progride continuamente e que por esta razão, mesmo teorias já consagradas precisam ser revistas em face de novas evidências.

\section{Como a ciência contribui para o ensino de leitura e de escrita desde a Educação Infantil?}

Nas escolas de Educação Infantil, é comum encontrar argumentos contrários ao ensino de linguagem escrita na pré-escola. Esses argumentos variam desde críticas de que as crianças pré-escolares ainda não estão desenvolvimentalmente aptas para aprender a ler e a escrever, até argumentos de que ensinar essas habilidades cerceia o direito das crianças de vivenciar a sua infância e o brincar (Abramowicz \& cols., 2009). Assim, no Brasil, as recomendações para os professores de Educação Infantil relacionadas a atividades de leitura e de escrita têm sido pouco específicas e mais relacionadas à narração de histórias, cantigas e parlendas, do que ao ensino de conhecimentos básicos sobre o sistema de escrita (ex., ensinar o alfabeto). Frequentemente essas recomendações baseiam-se em teorias desatualizadas e posicionamentos puramente ideológicos (Scliar-Cabral, 2013).

A multiplicação de pesquisas sobre a aprendizagem da leitura e da escrita, desde os anos 1970, possibilitou a criação do que se pode chamar de Ciência da Leitura (Snowling \& Hulme, 2013). A Ciência da Leitura se refere ao conjunto de evidências científicas sobre como as pessoas aprendem a ler e escrever e como se deve ensiná-las e tem se constituído com base em diferentes métodos e teorias oriundas de áreas do conhecimento como a Psicologia Cognitiva, que se refere ao estudo científico dos processos psicológicos (ex., atenção, linguagem, memória, raciocínio) envolvidos na aquisição de conhecimentos e processamento da informação (Maluf, 2015; Maluf \& Cardoso-Martins, 2013; Rayner, Foorman, Perfetti, Pesetsky, \& Seidenberg, 2001) e das Neurociências, sobretudo da Neurociência Cognitiva que é uma área interdisciplinar que em síntese se ocupa do estudo dos substratos neuronais subjacentes à cognição (Dehaene, 2012; Hruby, Goswami, Frederiksen, \& Perfetti, 2011; Maluf \& Sargiani, 2013).

Os conhecimentos provenientes da Ciência da Leitura têm sido essenciais para a elaboração de políticas públicas de alfabetização em países mais avançados, com diversos exemplos de sucesso, como por exemplo, na França, Portugal, Estados Unidos e Reino Unido. Entretanto esses conhecimentos ainda encontram dificuldades para serem incorporados nas políticas públicas brasileiras (Cardoso-Martins, Capovilla, Gombert, Oliveira, \& Morais, 2005).

Desde os anos 1980, muitas práticas de alfabetização no Brasil passaram a adotar pressupostos teóricos que enfatizavam mais a compreensão de textos, em detrimento da instrução para a aprendizagem do código alfabético (Maluf, 2015; Scliar-Cabral, 2013). Embora o uso de atividades direcionadas à compreensão de textos para suplementar a instrução explícita de correspondências letra-som ajude a tornar a alfabetização mais lúdica e significativa, essas atividades não deveriam substituir a instrução sobre o código alfabético, como frequentemente vem acontecendo no Brasil (Scliar-Cabral, 2013). A instrução fônica, isto é, o ensino explícito sobre as relações entre grafemas e fonemas, é criticamente importante e necessário, pois ajuda os alunos a compreender como funciona o sistema alfabético e a adquirir gradualmente a autonomia na leitura e na escrita (Scliar-Cabral, 2013) e também pode ser administrado de forma lúdica e significativa desde a Educação Infantil (Maluf \& Sargiani, 2015).

O conjunto de evidências da Ciência da Leitura revela que a aprendizagem da leitura e da escrita promove mudanças significativas no cérebro e na cognição, possibilitando novas formas de processamento de informações e de aquisição de conhecimentos (Dehaene, 2012; Morais, Leite, \& Kolinsky, 2013; Rayner \& cols., 2001). Quando se aprende a ler, áreas do cérebro que antes eram utilizadas para processar outros estímulos (ex., reconhecer faces e objetos) passam a constituir uma nova área especializada, a chamada Área da 
Forma Visual das Palavras (Visual Word FormArea - VWFA), localizada no giro fusiforme esquerdo, que responde principalmente ao processamento visual de letras e palavras escritas (Dehaene, 2012). Depois de "aprender a ler", as pessoas passam a "ler para aprender", isto é, passam a usar a leitura como um meio para obter diversos conhecimentos, o que faz das habilidades de leitura e de escrita, juntamente com as habilidades matemáticas, as bases fundamentais para o sucesso no processo de escolarização.

A leitura requer uma habilidade específica e um conjunto de capacidades mais ou menos gerais. A habilidade específica da leitura é a identificação de palavras escritas, e é específica porque embora tenha um grande impacto cognitivo - como na aquisição de conhecimentos - os circuitos cerebrais que a sustentam são criados durante a aprendizagem da leitura e só são utilizados para a atividade de ler (Dehaene, 2012; Morais \& cols., 2013). O conjunto de outras capacidades inclui: atenção, memória operacional, conhecimento lexical (vocabulário) e da gramática da língua, raciocínio, conhecimento semântico e enciclopédico (conhecimento de mundo), e capacidades de análise e de síntese. Essas capacidades são gerais, pois são partilhadas com outras funções cognitivas, e em especial com o processamento da linguagem oral (Morais \& cols., 2013).

Em resumo, ler é extrair pronúncia e significado a partir de materiais escritos com o objetivo de compreensão (Rayner \& cols., 2001). A compreensão em leitura depende de muitas habilidades cognitivas e linguísticas que são necessárias após a identificação ou o reconhecimento visual de palavras escritas. Por essa razão a compreensão é o objetivo principal da leitura, mas não é a leitura propriamente dita. A identificação ou reconhecimento de palavras escritas requer o domínio de uma técnica que permita extrair essas pronúncias e significados, e que consiste inicialmente na decodificação ou decifração, isto é, na extração de sons das letras seguindo um código ortográfico. Essa técnica deve ser ensinada pelos professores, enquanto as crianças também desenvolvem - em paralelo - as capacidades cognitivas e os conhecimentos linguísticos que lhes permitirão compreender os textos (Morais, 2013).

Escrever é registrar graficamente os sons da fala usando letras. É importante distinguir dois níveis de escrita. Em um nível mais elementar está a escrita de palavras, que é o que permite acesso ao segundo nível que consiste na escrita de textos, como os textos literários. Assim, a escrita de palavras é a base para a escrita de textos. Para além dos aspectos motores envolvidos na habilidade de escrita de palavras, enquanto ler é decodificar palavras escritas, escrever é o processo inverso, de codificação da fala usando sinais gráficos que são as letras (Morais \& cols., 2013). Para escrever, as pessoas dependem também da experiência de leitura, que possibilita a memorização de representações ortográficas na memória (Ehri, 2014)pronunciations, and meanings of specific words in memory. It explains how children learn to read words by sight, to spell words from memory, and to acquire vocabulary words from print. This development is portrayed by Ehri (2005a.
Ler e escrever são habilidades muito próximas e inter-relacionadas. Ambas seguem um curso de aquisição parecido e partilham muitos pré-requisitos, como o conhecimento sobre o sistema de escrita e a memória da grafia das palavras. As correlações entre leitura e escrita são fortes, tipicamente acima de $r=0,70$ (Ehri, 2000). Assim, leitura e escrita são como dois lados de uma mesma moeda, mas são dois processos distintos, principalmente porque para escrever é preciso recuperar mais informações na memória - como as letras corretas que devem ser usadas para escrever adequadamente as palavras - do que é necessário para ler, pois a maior parte da informação já está disponível para os leitores no material escrito (Ehri, 2000).

Alfabetizar é ensinar a ler e a escrever em um sistema alfabético, como o inglês, o espanhol, o italiano e o português. O acesso à alfabetização é uma conquista das sociedades democráticas que garantem, ou deveriam garantir a todos o direito de ascender à escola, lugar culturalmente escolhido para se ensinar a ler e a escrever. Os sistemas educacionais têm o dever, portanto, de garantir que suas escolas e seus professores criem e utilizem as práticas mais eficientes de ensino para favorecer a melhor aprendizagem. A evidência de que os alunos aprendem reflete e determina a qualidade dos sistemas educacionais, métodos de ensino, escolas e professores (Maluf \& Sargiani, 2015).

A análise dos resultados de avaliações nacionais e internacionais do desempenho de alunos brasileiros revela uma situação bastante delicada da educação brasileira. Assim, concordamos com alguns pesquisadores (Cardoso-Martins \& cols., 2005; Maluf \& Sargiani, 2015; Scliar-Cabral, 2013), que se faz urgente a assimilação de evidências de pesquisas no planejamento de políticas públicas de educação e a superação de escolhas de métodos de ensino fundamentadas em ideologias e convicções filosóficas, como tem acontecido no Brasil.

\section{Concepções sobre o desenvolvimento infantil e implicações pedagógicas}

Estudos sobre o desenvolvimento e a educação infantil defrontam-se frequentemente com questões sobre a idade em que as crianças devem começar a aprender a ler e escrever. Como existem diversas formas de enfocar a questão da aprendizagem da leitura e da escrita, também existem diferentes concepções sobre o desenvolvimento infantil que trazem implicações pedagógicas sobre o que deveria ou não ser ensinado para as crianças em determinados momentos. É nessa perspectiva que se coloca a questão sobre quando e como ensinar a ler.

De acordo com Rayner e colaboradores (2001) é possível distinguir três perspectivas principais sobre a aquisição da linguagem escrita: a) prontidão para a leitura, b) literacia emergente, e c) aprendizagem da linguagem escrita. A primeira é uma abordagem maturacional, conhecida como prontidão para a leitura. Dessa concepção deriva-se a ideia de que é preciso atingir uma certa idade e ter um desenvolvimento mínimo de diferentes habilidades para estar apto (pronto) 
a aprender a ler e a escrever. Assim, nessa abordagem é proposta a criação de testes para avaliar os níveis de conhecimentos e habilidades das crianças antes da alfabetização e determinar se estão prontas para serem ensinadas. Um exemplo aplicado dessa abordagem é o "Teste ABC: Para a verificação da maturidade necessária à aprendizagem da leitura e da escrita" criado no Brasil por Manuel Bergström Lourenço Filho em 1928 (Lourenço Filho, 2008).

A segunda abordagem, também desenvolvimental, é a chamada literacia emergente ou alfabetização emergente e considera que a leitura e a escrita se desenvolvem na sequência do desenvolvimento da linguagem oral, i.e., existe uma continuidade do desenvolvimento da linguagem oral para a linguagem escrita. Nessa perspectiva, as crianças são caracterizadas como desenvolvendo, desde muito cedo, conceitos sobre os componentes da leitura e da escrita, e seus desempenhos nas diferentes tarefas relacionadas à alfabetização são colocados em um continuum desenvolvimental. Essa abordagem conduz a uma menor ênfase no ensino de relações entre letras e sons, uma vez que se espera que as crianças desenvolvam a linguagem escrita naturalmente, por isso enfatizam-se abordagens mais holísticas que incluem muitas atividades de linguagem oral, leitura oral de textos feita pelas professoras e o uso de desenhos, cantigas e parlendas, como nas propostas derivadas da teoria da psicogênese da linguagem escrita (Ferreiro \& Teberosky, 1999).

A perspectiva desenvolvimental é particularmente importante por ressaltar que as crianças já ingressam na escola com muitos conhecimentos sobre atividades de leitura e de escrita (ex., conhecimentos sobre letras e livros). Entretanto, falha, pois algumas crianças podem até adquirir conhecimentos sobre como a escrita mapeia a fala de modo espontâneo ou ensinadas por seus pais, mas esses conhecimentos são parciais e limitados. A grande maioria das crianças precisa ser ensinada explicitamente em algum ponto da alfabetização sobre como funciona o sistema alfabético, principalmente pela necessidade de compreender como fonemas, ou seja, os menores sons das palavras são representados por grafemas, isto é, as letras (Maluf \& Sargiani, 2015).

Assim, aprender a ler e a escrever não é o ponto final de uma progressão desenvolvimental, mas é, mais frequentemente, o produto do ensino e da prática (Rayner \& cols., 2001). Por isso a terceira abordagem, da qual compartilhamos, considera que ler e escrever é um tipo específico de aprendizagem. As habilidades de leitura e de escrita são aprendidas e por esta razão devem ser ensinadas, pois não se desenvolvem naturalmente. Embora a aprendizagem da linguagem escrita se fundamente sobre as bases do desenvolvimento linguístico e cognitivo, na verdade as crianças precisam ser ensinadas sobre como a escrita mapeia a fala e como se deve ler e escrever. Depois de aprendido o mecanismo básico é que as crianças progridem ampliando e modificando seus conhecimentos; nesse sentindo passam a desenvolver as habilidades de leitura e escrita, o que é descrito em modelos teóricos como fases ou estágios do desenvolvimento da linguagem escrita (Ehri, 2000, 2014) pronunciations, and meanings of specific words in memory.
It explains how children learn to read words by sight, to spell words from memory, and to acquire vocabulary words from print. This development is portrayed by Ehri (2005a.

Essas diferentes perspectivas são adotadas implícita ou explicitamente em métodos de ensino de linguagem escrita e em diferentes modelos teóricos que descrevem as etapas da aquisição da leitura e da escrita. Assim, professores que acreditem que as crianças não estão aptas para aprender a ler e a escrever, ou que acreditem que não é necessário ensinar as relações entre letras e sons para as crianças, podem deixar as crianças mais à deriva da própria sorte para aprender a ler e a escrever, do que professores que saibam da necessidade de ensinar explicitamente como funcionam os sistemas de escrita (Rayner \& cols., 2001).

Além dessas perspectivas específicas sobre a aquisição da linguagem escrita, os professores também se fundamentam em concepções mais amplas sobre o desenvolvimento infantil que orientam as práticas pedagógicas. Segundo Siegler (1996), as teorias do desenvolvimento psicológico se baseiam implícita ou explicitamente em metáforas. A metáfora de escadas é a mais comum nas teorias mais antigas, como a da epistemologia genética de Jean Piaget. Seguindo essa metáfora, postula-se que as crianças pensam de uma determinada forma durante um período de tempo prolongado (semelhante a um degrau em uma escada) e assim resolvem seus problemas de uma única forma, até que são impelidas, seja pela maturação ou pelas experiências, a mudar em direção a uma forma de pensamento mais complexa, mais próxima à de adultos, como se subissem degraus em uma escada (ver Figura 1). De acordo com Siegler (1996) essa metáfora retrata as diferenças qualitativas entre o pensamento de crianças mais jovens e o pensamento de adultos, mas não explica exatamente como as crianças mudam de uma maneira de pensar para outra maneira mais complexa.
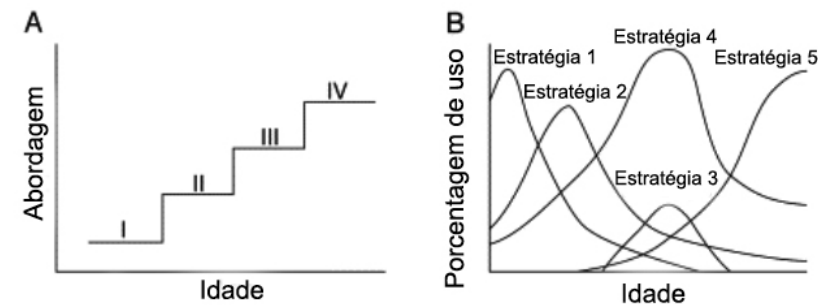

Figura 1. Esquema de modelos de escada $(A)$ e modelos de ondas (B) em teorias do desenvolvimento psicológico. Figura adaptada do original disponível em Siegler, R. S. (1996). Emerging Minds: The Process of Change in Children's Thinking. New York: Oxford University Press.

Siegler (1996) discute que novas evidências de pesquisa mostram que mesmo bebês utilizam várias estratégias para resolver problemas, o que contradiz teorias antigas baseadas em metáforas de escada. Assim, ele discute como novas teorias do desenvolvimento adotam uma metáfora 
de ondas que se sobrepõem, permitindo uma melhor explicação sobre como as crianças mesmo muito jovens usam diversas estratégias para resolver seus problemas, algumas mais avançadas outra menos até que predominam as mais eficientes (Siegler, 1996).

A metáfora de sobreposição de ondas permite teorizar sobre o desenvolvimento da seguinte forma: cada estratégia ou forma de pensar é como uma onda que se aproxima da beira do mar, com a altura de cada onda (frequência de utilização das estratégias) mudando continuamente, e diversas ondas sendo mais proeminentes em momentos diferentes, e com algumas ondas nunca sendo as mais proeminentes, mas ainda assim influenciando outras ondas e contribuindo para a maré (cf. Figura 1). Em diferentes momentos predominam tipos distintos de estratégias, mas é sempre possível retornar às estratégias anteriores se for necessário, por exemplo, quando a situação é nova ou quando se tem pouca experiência.

Assim, a metáfora de sobreposição de ondas nos leva a pensar que as crianças geralmente pensam sobre um determinado fenômeno de diversas maneiras, ao invés de ter apenas um único entendimento, limitado por seu estágio de desenvolvimento. Dessa forma, as crianças "não têm de estar em uma certa idade" para começar a adquirir algum conhecimento sobre alfabetização e nem são limitadas devido a seu estágio do desenvolvimento. Pelo contrário, se adquirem qualquer conhecimento (por exemplo, nomes de letras) antes do Ensino Fundamental, mesmo que não usem imediatamente, elas poderão usar esse conhecimento mais tarde para começar a aprender a ler.

Do ponto de vista cognitivo, também é importante dizer que as concepções anteriores de processamento de informações viam os processos cognitivos como uma sequência linear de etapas, o que é semelhante a um modelo (escada) passo-a-passo. No entanto, novas evidências das neurociências e de modelos conexionistas de desenvolvimento mostram que o cérebro humano difere em muitos aspectos do processamento serial de computadores (Elman, 2001). Vários processos paralelos acontecem ao mesmo tempo e de forma distribuída, a fim de processar qualquer informação. Modelos de processamento paralelo e distribuído (redes neurais) fornecem evidências de como o cérebro extrai regularidades da realidade e produz inferências a partir destas regularidades de modo não-linear, mas previsível (Elman, 2001).

Os estudos com seres humanos mostram que o período que segue desde o nascimento até aproximadamente seis anos representa um momento de intensa atividade e desenvolvimento cerebral e mental. O cérebro das crianças praticamente quadruplica de tamanho nesse período atingindo cerca de $90 \%$ do volume do cérebro adulto por volta dos seis anos. Entretanto, a quantidade de neurônios é praticamente a mesma desde o nascimento, as conexões entre eles é que se modificam, aumentam ou são eliminadas em virtude das experiências ambientais e culturais (Brown \& Jernigan, 2012).

Além disso, vários estudos sugerem que as crianças aprendem mais do que se supunha anteriormente e mais cedo (Brown \& Jernigan, 2012; Kuhl, 2011; Siegler, 1996). Essas pesquisas mostram que bebês aprendem por "aprendiza- gem estatística", isto é, uma forma implícita de aprendizagem que ocorre quando a criança interage com o mundo e extrai e processa regularidades, por exemplo, para adquirir a linguagem falada e a sua cultura (Kuhl, 2007, 2011). Assim como os modelos conexionistas demonstram, o cérebro dos bebês é altamente capacitado para extrair e computar regularidades do ambiente que permitem que eles aprendam uma série de informações, muito antes do que teorias antigas do desenvolvimento supunham (Elman, 2001; Kuhl, 2011).

Em conjunto, essas evidências fornecem subsídios para a ideia de que as crianças que recebem estímulos adequados precocemente podem aprender e ter benefícios desses estímulos, mesmo que elas não possam utilizar os seus conteúdos imediatamente, eles criam a base para aprendizagens futuras. É evidente que as crianças muito pequenas ainda não desenvolveram completamente algumas habilidades psicológicas, por exemplo, elas têm baixo limiar de atenção e vocabulário limitado, mas são justamente as experiências que potencializam o desenvolvimento dessas habilidades. Um professor pode, por exemplo, adaptar as suas instruções para que as crianças possam ter de se concentrar por menos tempo e aprender pelo menos alguns elementos básicos como as letras, ainda que não sejam alfabetizadas na Educação Infantil. Com o passar do tempo, as instruções serão complementadas, revisadas e ampliadas ajustando-se às novas habilidades das crianças.

Embora a maioria das crianças, muitas vezes, não receba instrução formal em leitura e escrita até que entre no primeiro ano do Ensino Fundamental, as pesquisas mostram que alguns conhecimentos e habilidades que podem ser ensinados na Educação Infantil, se mostram importantes para o sucesso na alfabetização (Hulme \& Snowling, 2013). Denominam-se esses de precursores de habilidades iniciais de alfabetização ou habilidades fundamentais de alfabetização. Trata-se de habilidades, conhecimentos e atitudes em relação à leitura e escrita, que quando desenvolvidos antes da instrução formal, predizem o sucesso na aquisição de habilidades convencionais de alfabetização, como a decodificação, a fluidez na leitura oral, a compreensão de leitura, a escrita e a ortografia (National Early Literacy Panel, 2008).

Em uma meta-análise de mais de 500 estudos empíricos (National Early Literacy Panel, 2008) foram encontrados seis precursores que mantiveram seu poder preditivo mesmo quando o papel de outras variáveis, como o QI ou o status socioeconômico, foram contabilizados: conhecimento alfabético, isto é, conhecer os nomes e sons das letras; consciência fonológica, capacidade de detectar, manipular e analisar os aspectos sonoros da fala, independentemente dos significados; nomeação automática rápida (RAN) de letras e dígitos, que se expressa na habilidade de nomear rapidamente uma sequência aleatória de letras ou dígitos; RAN de objetos e cores, habilidade de nomear rapidamente sequências aleatórias de objetos ou cores; escrita inicial e escrita do próprio nome, ou seja, escrever letras isoladas quando solicitado ou o próprio nome; e memória fonológica, entendida como a habilidade de recordar informações faladas por um curto período de tempo. 
Além dessas habilidades, os resultados da meta-análise também indicaram outras cinco que foram moderadamente correlacionadas com pelo menos uma medida posterior de alfabetização, mas não mantiveram esse poder preditivo, quando outras variáveis foram contabilizadas: conceitos sobre a escrita: conhecimento de convenções de escrita (por exemplo, lê-se da esquerda para a direita, de frente para trás) e conceitos (capa de livro, autor, texto); conhecimento de escrita: uma combinação de elementos de conhecimento alfabético, conceitos sobre a escrita e decodificação precoce; prontidão para a leitura: uma combinação de medidas como conhecimento alfabético, conceitos de escrita, vocabulário, memória e consciência fonológica. linguagem oral: a capacidade de produzir ou compreender linguagem falada, incluindo vocabulário e gramática;processamento visual: a capacidade de combinar ou discriminar símbolos visualmente apresentados.

Vários estudos atestam a importância do desenvolvimento de habilidades fundamentais de alfabetização na Educação Infantil para prevenir dificuldades no processo de alfabetização (Hruby \& cols., 2011; Hulme \& Snowling, 2013; National Early Literacy Panel, 2008). Isso implica na necessidade de que as escolas de Educação Infantil incluam, em seus currículos, atividades que facilitem o desenvolvimento dessas habilidades, superando as diferenças individuais e garantindo que todas as crianças possam ter condições apropriadas para aprender a ler e a escrever.

\section{Considerações Finais}

No Brasil, pouca ênfase tem sido dada ao ensino e à aprendizagem na Educação Infantil, pois enfatiza-se o desenvolvimento espontâneo das crianças por meio de jogos e brincadeiras com a recusa de atividades mais estruturadas e diretivas (Arce \& Martins, 2007), principalmente as atividades relacionadas ao ensino inicial de leitura e escrita. Entretanto, as atividades oferecidas na Educação Infantil podem ser ao mesmo tempo lúdicas, estruturadas e direcionadas para possibilitar a aquisição de habilidades e competências necessárias para o desenvolvimento global das crianças e para a aprendizagem de conteúdos que serão necessários para o Ensino Fundamental, sem privá-las de outras vivências e experiências comuns à primeira infância.

O conjunto de evidências das Neurociências e da Psicologia Cognitiva tem mostrado que as crianças não são limitadas por sua idade como se pensava anteriormente; o que hoje se sabe é que o ensino impulsiona o desenvolvimento infantil (Siegler, 1996). Os marcos cronológicos são apenas referências gerais, pois a base do desenvolvimento é determinada nas e pelas condições concretas e reais da vida das crianças (Arce \& Martins, 2007). Uma Educação Infantil de qualidade deve propiciar que todas as crianças adquiram conhecimentos e habilidades que as coloquem em condições de igualdade para terem sucesso no processo de escolarização e uma vida plena e feliz.
Além disso, aprender a ler e escrever não é uma consequência natural do desenvolvimento da linguagem oral. Para ser alfabetizado é necessário ser explicitamente ensinado sobre como as letras representam sistematicamente os sons da fala. Assim, mesmo que as crianças não sejam alfabetizadas na Educação Infantil, podem-se introduzir, nesse período, práticas de ensino que sejam facilitadoras da alfabetização. Crianças por volta dos quatro ou cinco anos já têm plenas condições de aprender, por exemplo, os nomes, formas e sons das letras, o que será fundamental para facilitar sua posterior alfabetização.

\section{Referências}

Abramowicz, A.; Levcovitz, D.; Rodrigues, T. C. (2009). Infâncias em Educação Infantil. Pro-Posições, 20(3), 179-197.

Arce, A.; Martins, L. M. (2007). Quem tem medo de ensinar na Educação Infantil? Em defesa do ato de ensinar (3a ed.). Campinas,SP: Alínea.

Brown, T. T.; Jernigan, T. L. (2012). Brain development during the preschool years. Neuropsychol Rev., 22(4), 313-333. Doi: https:// doi.org/10.1038/nature13314.A

Burger, K. (2010). How does early childhood care and education affect cognitive development? An international review of the effects of early interventions for children from different social backgrounds. Early Childhood Research Quarterly, 25(2), 140-165. Doi: https:// doi.org/10.1016/j.ecresq.2009.11.001

Cardoso-Martins, C.; Capovilla, F. C.; Gombert, J.-É.; Oliveira, J. B. A.; Morais, J. (2005). Os novos caminhos da alfabetização infantil. (F. C. Capovilla, Ed.) (2a. ed.). São Paulo: Menon.

Dehaene, S. (2012). Os Neurônios da Leitura: Como a Ciência Explica a Nossa Capacidade de Ler. Porto Alegre: Penso.

Ehri, L. C. (2000). Learning to read and learning to spell- Two sides of a coin. Topics in Language Disorders, 20, 19-36.

Ehri, L. C. (2014). Orthographic Mapping in the Acquisition of Sight Word Reading, Spelling Memory, and Vocabulary Learning. Scientific Studies of Reading, 18(1), 5-21. Doi: https://doi.org/10. 1080/10888438.2013.819356

Elman, J. L. (2001). Connectionism and language acquisition. Language Development: The Essential Readings, 295-306. Doi: https://doi.org/10.1080/016909698386483

Ferreiro, E.; Teberosky, A. (1999). Psicogênese da Língua Escrita. Porto Alegre: Penso.

Hart, B.; Risley, T. R. (1995). Meaningful Differences in the Everyday Experience of Young American Children. Baltimore: Brookes. 
Hart, B.; Risley, T. R. (2003). The Early Catastrophe: The 30 Million Word Gap by Age 3. American Educator, 27(1), 4-9.

Hruby, G. G.; Goswami, U.; Frederiksen, C. H.; Perfetti, C. A. (2011). Neuroscience and Reading: A Review for Reading Education Researchers. Reading Research Quarterly, 46(2), 156-172. Doi: https://doi.org/10.1598/RRQ.46.2.4

Hulme, C.; Snowling, M. J. (2013). Learning to read: What we know and what we need to understand better. Child Development Perspectives, 7(1), 1-5. Doi: https://doi.org/10.1111/cdep.12005

Kuhl, P. K. (2007). Is speech learning "gated" by the social brain? Developmental Science, 10(1), 110-20. Doi: https://doi. org/10.1111/j.1467-7687.2007.00572.x

Kuhl, P. K. (2011). Early Language Learning and Literacy: Neuroscience Implications for Education. Mind, Brain and Education: The Official Journal of the International Mind, Brain, and Education Society, 5(3), 128-142. Doi: https://doi.org/10.1111/ j.1751-228X.2011.01121.x

Lourenço Filho, M. B. (2008). Teste ABC: Para a verificação da maturidade necessária à aprendizagem da leitura e da escrita. Brasília, DF: INEP.

Maluf, M. R. (2015). Ensinar a Ler : Progressos da Psicologia no Século XXI. Boletim Academia Paulista de Psicologia, 35(89), 309-324.

Maluf, M. R.; Cardoso-Martins, C. (2013). Alfabetização no Século XXI: Como se Aprende a Ler e a Escrever. (M. R. Maluf \& C. Cardoso-Martins, Eds.) (1st ed.). Porto Alegre: Penso.

Maluf, M. R.; Sargiani, R. de A. (2013). Lo que la neurociencia tiene que decir sobre el aprendizaje de la lectura. Revista de Psicología de Arequipa, 3(1), 11-24.

Maluf, M. R.; Sargiani, R. deA. (2015). Alfabetização e metalinguagem: condições para o ensino eficiente da linguagem escrita. In:Naschold, A. C.;Pereira, A.;Guaresi, R.;Pereira,V. W. (Orgs.), Aprendizado da leitura e da escrita: a ciência em interfaces (pp. 237-255). Natal: EDUFRN.

Morais, J. (2013). Criar leitores - Para professores e educadores. São Paulo, SP: Manole.

Morais, J.; Leite, I.; Kolinsky, R. (2013). Entre a pré-leitura e a leitura hábil: Condições e patamares da aprendizagem. In:Maluf,M. R.;CardosoMartins,C. (Orgs.), Alfabetização no século XXI: Como se aprende a ler e a escrever (pp. 17-48). Porto Alegre: Ed. Penso/Artmed.

National Early Literacy Panel (2008). Developing early literacy: Report of the National Early Literacy Panel. Developing early literacy:
Report of the National Early Literacy Panel. Washington, DC. Doi: https://doi.org/10.1598/RRQ.45.1.2

Rayner, K.; Foorman, B. R.; Perfetti, C. A.; Pesetsky, D.; Seidenberg, M. S. (2001). How psychological science informs the teaching of reading. Psychological Science: A Journal of the American Psychological Society / APS, 2(2 Suppl), 31-74. Doi: https://doi. org/10.1111/1529-1006.00004

Scarborough, H. S. (2001). Connecting early language and literacy to later reading (dis)abilities: Evidence, theory, and practice. In:Neuman,S. B.;Dickinson,D. K. (Orgs.), Handbook of early literacy research(Vol. 1.,pp. 97-110). New York: Guilford Press.

Scliar-Cabral, L. (2013). A desmistificação do método global. Letras de Hoje, 48(1), 6-11.

Siegler, R. S. (1996). Emerging Minds:The Process of Change in Children's Thinking. New York: Oxford University Press.

Silva, J. C.; Hai, A. A. (2013). O impacto das concepções de desenvolvimento infantil nas práticas pedagógicas em salas de aula para crianças menores de três anos. Perspectiva (UFSC), 30(3), 1099-1123. Doi: https://doi.org/http://dx.doi.org/10.5007/2175795X.2012v30n3p1099

Snowling, M. J.; Hulme, C. (2013). A Ciência da Leitura. Porto Alegre: Penso.

Stein, A.; Malmberg, L. E.; Leach, P.; Barnes, J.; Sylva, K.; Davies, B.; ... Walker, J. (2013). The influence of different forms of early childcare on children's emotional and behavioural development at school entry. Child: Care, Health and Development, 39(5), 676687. Doi: https://doi.org/10.1111/j.1365-2214.2012.01421.x

Tunmer, W. E. (2013). Como a ciência cognitiva forneceu as bases teóricas para a resolução do "grande debate" sobre métodos de leitura em ortografias alfabéticas. In:Maluf,M. R.;CardosoMartins,C. (Orgs.), Alfabetização no século XXI: Como se aprende a ler e a escrever (pp. 124-137). Porto Alegre: Penso.

Tunmer, W. E.; Chapman, J. W.; Prochnow, J. E. (2006). Literate cultural capital at school entry predicts later reading achievement: A seven year longitudinal study. New Zealand Journal of Educational Studies, 41(2), 183.

Zauche, L. H.; Thul, T. A.; Mahoney, A. E. D.; Stapel-Wax, J. L. (2016). Influence of language nutrition on children's language and cognitive development:An integrated review. Early Childhood Research Quarterly, 36, 318-333. Doi: https://doi.org/10.1016/j.ecresq.2016.01.015

Recebido: 21 de dezembro de 2016 Aceito: 12 de fevereiro de 2018

(cc) EY License information: This is an open-access article distributed under the terms of the License (type CC-BY), which permits unrestricted use, distribution and reproduction in any medium, provided the original article is properly cited. 